increasing population, and "other imponderables," no one had any real idea.

Hardly anyone welcomed the new medical assistant grade. The Joint Consultants Committee finally agreed to it only after it was established that such a grade was needed. But Sir Thomas Holmes Sellors was neither happy about its title nor entirely happy about its future, and he found it difficult to say who would fill the grade. Even the safeguards against abuse of it, generally considered satisfactory, were doubted by some. Mr. Vernon Jones, who saw medical assistants as S.H.M.O.s in a different guise, pointed out that there were over 2,000 ready-made candidates for medical-assistant posts among existing S.H.M.O.s, senior casualty officers, and junior hospital medical officers, who would be regarded as medical assistants " almost overnight." His prophecy that even after five years there would be insufficient consultants and that therefore medical assistants would be doing consultant work at lower rates of pay may prove to be too gloomy, but it cannot be dismissed as fanciful. Nor can the fear expressed by Dr. E. A. Harvey-Smith, chairman of the Hospital Junior Staffs Group Council, that young hospital doctors stuck on the way up could be side-tracked into what he thought would be the dead-end of a medical assistant job. His thoughtful speech touched on many aspects of the hospital service, and he was speaking for some 13,000 younger doctors. They have made some notable contributions to medico-political thinking in recent years.

Finally, in discussing the place of the consultants' representative organization in the B.M.A. and its relationship to the Joint Consultants Committee, the conference touched on a subject which will figure large in the affairs of the Association in the current session. A special committee is known to be reviewing the B.M.A.'s constitution and it will be reporting to the Council shortly. The Conference debate thus served as a curtain-raiser to the many other and more lengthy ones which are likely to take place. Meanwhile, few will dissent from Dr. J. S. Noble's view that professional unity must be based on understanding and not on organization. A good organization, however, can be of help in preventing misunderstandings.

\section{Diabetes and Neuropathy}

The number of conditions recognized as causing polyneuropathy continues to rise, despite the increasing rarity of some old favourites such as lead poisoning or diphtheria. Though everyone is familiar. with diabetic neuropathy, few are probably aware that, in complete contrast, hypoglycaemia may be a potent if uncommon cause. L. Rosner and R. Elstad ${ }^{1}$ have now reviewed 25 cases of polyneuropathy associated with hypoglycaemia. The series is made up from scattered reports of isolated cases, the nine described by E. H. Lambert and his colleagues" from the Mayo Clinic and four of their own. It is clear that polyneuropathy is usually found late in the course of the disease, or quite incidentally; but in four patients it was the presenting symptom. All 25 patients had islet-cell tumours of the pancreas; they had long histories, and the severity of the neuropathic symptoms appears to have been related to the depth of the hypoglycaemia. There are no pathognomonic features of this type of polyneuropathy, though the cases have tended to show several features in common. First, there is a striking tendency for it to be entirely or predominantly motor in character; secondly, considerable atrophy of the small muscles of the hand is often prominent ; and, thirdly, the symptoms tend to increase for a few weeks after removal of the insulinoma, with good recovery subsequently.

Hence patients showing episodic mental confusion, disturbances of behaviour, ${ }^{3}$ and, of course, coma, together with a motor polyneuropathy, and who might perhaps be suspected of having some other metabolic disturbance (such as acute intermittent porphyria), must also have careful estimations of the sugar in the blood carried out-not only as isolated readings, but also after prolonged starvation and under electroencephalographic control, for insulinoma is eminently treatable.

It is uncertain whether the lesion lies in the peripheral nerves, the spinal roots, or the anterior horn cells. The entirely motor involvement in some cases, combined at times with retention or even exaggeration of reflexes, produces a picture resembling motor neurone disease. Fragmentation of anterior horn cells has in fact been shown in two cases examined at necropsy, ${ }^{45}$ but, on the other hand, many patients have shown loss of sensation, and electromyographic studies ${ }^{6}$ would support involvement of the peripheral nerves. In fact probably both sites are affected, the dominance of one over the other varying in individual cases. Certainly hypoglycaemia induced in animals has been found to cause degenerative changes in both anterior horn cells and posterior root ganglia. ${ }^{78}$

The aetiology and pathology of the much more common diabetic neuropathy have also been a subject of controversy. Is there a primary degeneration of the peripheral nerves, due perhaps to some metabolic defect, or are these changes secondary to defective blood-supply from occlusive disease of the vasa nervorum ? ${ }^{9} \mathrm{D}$. Greenbaum and his colleagues ${ }^{10} 11$ have recently studied the natural history of 80 cases of diabetic neuropathy and carried out pathological studies in six, in which most of the clinical manifestations were represented. The pathological findings were similar in all, but varied in extent and severity. They consisted of loss of large myelinated fibres in the peripheral nerves, of neurones in the posterior root ganglia, and sometimes of anterior horn cells. There were no lesions in the vasa nervorum. They believe diabetic neuropathy to be a homogeneous disease despite its varied methods of presentation, and to be " a primary neuronal degeneration affecting the lower motor neurone and primary sensory neurones independent of vascular disease."

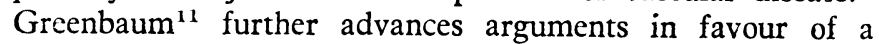
metabolic defect as the precipitating cause, emphasizing that the disease can be reversed or arrested by adequate treatment, even if the symptoms seem to have appeared after treatment has started.

${ }^{1}$ Rosner, L., and Elstad, R., Neurology (Minneap.), 1964, 14, 1.

"Lambert, E. H., Mulder, D. W., and Bastron, J. A., ibid., 1960, 10, 851. Todd, J., Collins, A. D., Martin, F. R. R., and Dewhurst, K. E., Brit. med. F., 1962, 2, 828. "Tom, M.' I., and Richardson, J. C., F. Neuropath. exp. Neurol., 1951,
10, 57.

Moersch, F. P., and Kernohan, J. W., Arch. Neurol. Psychiat. (Chicago), $1938,39,242$.

${ }^{6}$ Mulder, D. W., Bastron, J. A., and Lambert, E. H., Neurology (Minneap.), $1956,6,627$.

Winkelman, N. W., and Moore, M. T., Arch. Neurol. Psychiat. (Chicago), 1940, 43, 1108.

'Tannenberg, J., Proc. Soc. exp. Biol. (N.Y.), 1939, 40, 94.

"W'oltman, H. W., and Wilder, R. M., Arch. intern. Med., 1929, 44, 576. Greenbaum, D., Richardson, P. C., Salmon, M. V., and Urich, H., Brain, 1964, 87, 201.

11 ibid., 1964, 87, 215.

1.: Simpson, J. A., Brit. med. .7., 1964, 2, 709. 
In several ways these two types of neuropathy are similar, but in view of Rosner and Elstad's findings the question must arise whether a polyneuropathy developing in an unstable diabetic on treatment must always be attributed to the diabetes, or whether repeated swings to hypoglycaemia might not be a contributory factor. Though this is one of the rare causes, the proportion of cases of polyneuropathy in which the primary cause is not discovered is so high-over 50 ".., according to J. A. Simpson's recent review 12 - that any increase in our knowledge of the condition will be welcomed by clinicians.

\section{Absence of Neutrophils}

The observations of Bordet, Ehrlich, and Metchnikoff in the nineteenth century established that the resistance of the body to bacterial infection was based on two main factors-first, the immune mechanism and, secondly, the phagocyte activity of the white cells in the blood. Any failure of either of these mechanisms results in a predisposition to recurrent infections.

Chronic granulocytopenia which is not due to a specific disease process such as leukaemia, aplastic anaemia, marrow replacement, or "hypersplenism" is uncommon. Cases in adult life $\mathrm{i}^{-3}$ usually have a persistent neutropenia with reduced numbers of granulocytic precursors in the bonemarrow. More rarely the episodes of neutropenia appear every three or four weeks accompanied by fever, malaise, and often severe ulceration of the mouth. This form has been termed cyclic or periodic neutropenia. ${ }^{4:}$ The prognosis in the adult form is relatively good, though mouth ulceration and repeated respiratory-tract infection remains troublesome. The aetiology is obscure, though in a few patients an autoimmune mechanism has been suggested..$^{6}{ }^{i}$ The mixed cell agglutination reaction is probably the most convenient method of demonstrating the presence of leucocytes sensitized by an autoantibody, but the test is made more difficult because patients with this condition have so few white cells in their blood-stream.

- Chronic neutropenia appearing in childhood is relatively more common than the form in adult life; the outlook is less favourable and many cases die from the episodes of infection. The frequency of the disorder in siblings suggests that in many cases the failure of the production of neutrophil leucocytes is determined genetically. Thus the disorder may be transmitted as a dominant ${ }^{89}$ or as a recessive characteristic, as in the families described by $\mathrm{R}$. Kostmann ${ }^{10}$ among the Lapps in North Sweden. Films of bone-marrow usually show granulocytic precursors up to the metamyelocyte or stab stage but very few mature neutrophil polymorphonuclear leucocytes.

Recently W. W. Zuelzer ${ }^{11}$ and C. E. Krill and his colleagues $^{12}$ have described two children with chronic neutro-

\footnotetext{
'Hattersley, P. G., Blood., 1947, 2, 227.

2 Adams, E. B., and Witts, L. J., Quart. F. Med., 1949, 18, 173

${ }_{3}$ Spaet, T. H., and Dameshek, W., Amer. F. Med., 1952, 13, 35

4 Sutton, R. L., F. cut. Dis., 1911, 29, 65 .

5 Reimann, H A Medicine (Baltimore), 1951, 30, 219.

${ }^{6}$ Walford, R. L., Leukocyte Antigens and Antibodies, $1959 . \quad$ Grune and Walford, R. L., Leukocyte
Stratton, New York.

'Mårtensson, J., and Vikbladh, I., Blood, 1954, 9, 632.

'Martensson, J., and Vikbladh, I., Blood, 1954,

9 Gänsslen, M., Klin. Wschr., 1941, 20, 922.

Kostmann, R., Acta paediat. (Stockh.), 1956, 45, Supp. 105

Zuelzer, W. W., New Engl. F. Med., 1964, 270, 699.

1: Krill, C. E., Smith, H. D., and Mauer, A. M., ibid., 1964, 270, 973.
}

penia which differed in some respects from other reported cases. Studies of the bone-marrow showed not only myeloid precursors but also many mature neutrophils which, nevertheless, were absent from the peripheral blood. These neutrophils in the marrow were morphologically abnormal with cytoplasmic vacuoles, heavy granulation, and pyknotic nuclear lobes connected by long thin strands of chromatin. Krill and his colleagues were able to label these leucocytes with di-iso-propyl phospho-fluoridate- ${ }^{32} \mathrm{P}$ (DFP-32), and demonstrated an impaired survival of these cells both in the patients' own circulation as well as in the circulation of a normal recipient. Zuelzer found that many of these cells had a reduced viability, as indicated by an abnormal permeability to dyes, and that they were also poorly active in phagocytosis. The term " myelokathexis" (indicating retention of neutrophils in the marrow) and chronic idiopathic granulocytopenia have been proposed for this variant of chronic neutropenia, but probably the question of nomenclature should await more decisive demonstration that these cases are aetiologically different from other examples of chronic neutropenia.

\section{Nursing Administration}

Nurses have always taken a lively interest in their training, and the large number of excellent reports on nursing education - the most recent of which appeared this June'-has done much to create the high standards of nursing in Britain. Yet despite the fundamental changes in medicine in the past century little has been said, and even less done, about the administrative pattern of the profession. Florence Nightingale would probably notice little difference between nursing administration in her day and ours-but it is doubtful whether her contemporary Dr. Henry Bence Jones would be equally at home in the administrative maze that surrounds the modern teaching hospital.

In 1959 the Royal College of Nursing, recognizing the unsatisfactory pattern of nursing administration, and particularly the shortage of suitable applicants for posts, set up a working party to study the position. Its report, recently published," suggests that there are probably two main reasons why the traditional structure has persisted for so long. Firstly, the nursing profession and hospital authorities alike have continued to regard nurses as a highly dedicated group, prepared to work long hours around the clock and to undertake domestic and other non-nursing duties. Secondly, nurses' pay has until recently been kept at a very low level. Those higher up the career ladder also have grounds for discontent. Nurse administrators, such as assistant matrons and administrative sisters, though poorly paid, may have heavy responsibilities which all too often bear little relation to nursing. Nurse tutors often believe, "that the importance of nursing education is not adequately recognized and that the circumstances in which they have to work make their task an impossible one." Again, a ward sister can rise higher in the profession only by forsaking clinical responsibility for administration or teaching. All these reasons, accelerated by present-day conditions-particularly the excess of demand

1 Brit. med. 7., 1964, 1, 1585

2 Administering the Hospital Nursing Service-A Review, 1964, price $3 s$. Royal College of Nursing, London. 